Like most controversial topics in medicine, the truth probably lies between the two schools of thought. In the early acute ease-roughly within the first 48 hours-operation is indeed quite simple and there is no contraindication to its performance in an otherwise fit patient provided a skilled surgeon is available and that there are full facilities for operative cholangiography: Surgery is also indicated if the gall bladder has perforated before admission or if the disease does not settle with conservative treatment, when a cholecystotomy is usually necessary. However, in the patient whose acute attack has been in progress for some days, or who is grossly fat or a poor risk or who is in a hospital where adequate operative facilities are not available, a conservative regimen is the wiser course-better a living problem than a dead certainty.

\section{Nonbacterial Vegetations on the Heart Valves}

Nonbacterial vegetations are seen on the heart valves in rheumatic carditis and the Libman-Sacks endocarditis of systemic lupus erythematosus. ${ }^{1}$ They consist of platelet aggregates covered with fibrin, and they arise on areas of inflammation and necrosis in the valve substance. Vegetations may also occur on valves that are apparently normal in the condition of nonbacterial thrombotic endocarditis-sometimes called terminal endocarditis because it is usually considered a terminal phenomenon of little clinical significance. ${ }^{23}$ In one series it was noted in 78 of 18,486 consecutive necropsies, and in 11 cases there was systemic embolism with infarction, which was in some instances the immediate cause of death, ${ }^{4}$ an indication that the condition is not always terminal. It is specially prone to complicate widespread cancer, ${ }^{56}$ but it may occur in many other conditions and may be the first indication of a systemic disease. $^{4}$

The valves affected are usually the mitral and the aortic, which show slight degenerative changes in the collagen framework without a cellular reaction. It has been suggested that altered collagen forms the bulk of the vegetations, ${ }^{7}$ but they are in fact thrombi developing on slightly abnormal valves. $^{5}$ It is likely that in some cases the clotting time of the blood is decreased. ${ }^{6}$ The vegetations may become organized, and it is possible that the common Lambl's excrescences, small filiform processes found on the valves of elderly people, have their origin in minute thrombi of this nature. ${ }^{8}{ }^{9}$

Nonbacterial valvular vegetations can be produced experi-

1 Libman, E., and Sacks, B., Arch. intern. Med., 1924, 33, 701.

2 F. Amer. med. Ass., 1923, 80, 813.

- Gross, L., and Friedberg, C. K., Arch. intern. Med., 1936, 58, 620.

- MacDonald, R. A., and Robbins, S. L., ibid., 1957, 46, 255.

- Barry, W. E., and Scarpelli, D., Circulation, 1961, 24, 882.

- Smith, J. P., and Yates, P. O., F. Path. Bact., 1955, 70, 111.

- Allen, A. C., and Sirota, J. H., Amer. F. Path., 1944, 20, 1025.

- Margarey, F. R., 7. Path. Bact., 1949, 61, 203.

- Pomerance, A., ibid., 1961, 81, 135.

10 Lillehei, C. W., Bobb, J. R. R., and Visscher, M. B., Ann. Surg., 1950, 132, 577.

11 - Shaffer, J. M., Spink, W. W., Bobb, J. R. R., Wargo, J. D., and Visscher, M. B., ibid., 1951, 63, 421.

12 Nakao, K., and Angrist, A. A., Brit. f. exp. Path., 1967, 48, 294.

13 Angrist, A. A., Oka, M., Nakao, K., and Marquiss, J., Amer. F. Path., $1960,36,181$.

14 Asboe-Hansen, G., in International Review of Connective Tissue Research, ed. Hall, D. A., New York, 1963, p. 29.

is Anderson, H. J., and Staffurth, J. S., Lancet, 1955, 2, 1055.

16 Wallach, J. B., Glass, M., Lukash, L., and Angrist, A. A., Ann. intern. Med., 1955, 42, 1206 mentally in animals by creating an arteriovenous fistula between the femoral or iliac arteries and veins or between the aorta and the inferior vena cava. ${ }^{10}$ These vegetations are apt to become infected spontaneously, and if bacteria are injected intravenously a bacterial endocarditis invariably results. ${ }^{11}$ It is possible that the cardiovascular stress produced as a result of the shunt leads to minor valve damage which predisposes to thrombosis and bacterial infection. Recently $K$. Nakao and A. A. Angrist have studied the pathogenesis of these valvular lesions in rats in which arteriovenous fistulae had been produced between the aorta and the inferior vena cava below the renal vessels. ${ }^{12}$ They found that the first changes occurred in the loose connective tissue underneath the endothelial basement membrane. There was an oedematous dissociation of the collagen fibres, due probably to a biochemical change in the ground substance. At the site of these lesions there was a patchy denudation of endothelial cells, and platelet aggregation tended to occur on the fibrinoid material consisting of collagen fibres, fibrin, and acid mucopolysaccharide. A constant feature of this type of experiment is hyperplasia of the adrenals. Its cause is unknown, but it has been suggested that excessive production of glucocorticoids plays a part in the connective tissue changes in the valves. ${ }^{13} 14$

While this experimental work seems to have no immediate application to man, it serves to throw light on the pathogenesis of both nonbacterial thrombotic endocarditis and the bacterial variety, which is a serious complication of pre-existing valvular disease and congenital heart disease. It is interesting that subacute bacterial endocarditis is not uncommon in the elderly, and that in the majority of cases there is no gross valvular disease to account for its localization. ${ }^{15}{ }^{16}$ It is likely that these "virgin valves" 15 are the seat of nonbacterial thrombotic endocarditis which subsequently becomes infected. It is evident that this variety of vegetation is not necessarily a terminal event or of little clinical importance. In a study of its pathogenesis may lie a greater understanding of the mechanism of bacterial localization in the infective type of endocarditis.

\section{Acute Necrotizing Encephalitis}

"Encephalitis" is one of the most unsatisfactory clinical diagnoses in neurology. If the illness is mild the patient recovers and the diagnosis is rarely firmly established, while in those seriously ill the diagnosis is often incorrect and if too readily made may mask until too late some lesion such as a tumour or an abscess which may have required urgent surgical treatment. Several devastating affections of the brain which are apparently encephalitic have been classified pathologically, but clinical diagnosis is very difficult and in few of these conditions is either the aetiology or the treatment clear. However, one condition-acute necrotizing encephalitis-is being clinically recognized more frequently by neurologists and neurosurgeons, and evidence is growing that many of these cases are due to the herpes simplex virus. J. Hume Adams and W. Bryan Jennett ${ }^{1}$ have recently described eight typical cases and list most of the published accounts. The earlier literature is reviewed by $\mathbb{W}$. Haymaker and his colleagues $^{2}$ and by $\mathrm{L}$. van Bogaert and his colleagues. ${ }^{3}$

The disease occurs at all ages and the sexes are equally affected. There may be a prodromal illness with general 